\title{
A ESTÉTICA NEOFANTÁSTICA NO ROMANCE AS HORAS NUAS, DE LYGIA FAGUNDES TELLES
}

\author{
THE NEOFANTASTIC AESTHETIC IN THE NOVEL AS HORAS \\ NUAS BY LYGIA FAGUNDES TELLES
}

Kelio Junior Santana Borges ${ }^{1}$

\begin{abstract}
Resumo: Este trabalho tem o propósito de promover uma análise estrutural e semântica do universo sobrenatural presente no romance As horas nuas, de Lygia Fagundes Telles. Nosso estudo almeja estudar o livro à luz de teorias outras que distanciam sobrenatural contemporâneo daquele tradicional pertencente aos séculos XVIII e XIX. Para isso, teremos como norte as palavras do escritor italiano Italo Calvino - em quem nos apoiaremos para promover uma leitura mais atual desse universo metafísico - assim como a teoria do argentino Jayme Alazraki - estudioso responsável pela criaçăo do termo neofantástico, palavra com que define essa forma derivada da antiga narrativa fantástica, aquela tâo amplamente teorizada por Tzvetan Todorov.
\end{abstract}

Palavras-chave: Sobrenatural. Fantástico. Neofantástico. Lygia Fagundes Telles.

Abstract: This research aims to promote a structural and semantical analysis of the supernatural universe in the novel As horas nuas (1989), by Lygia Fagundes Telles. This study intends to discuss the book according to theories that distance themselves from the traditional supernatural, contemporary to the XVIII and XIX centuries. In order to do so,we will take into account the words of the Italian writer Calvino - on which this paper is based to promote a more recent reading of the metaphysical universe - as well as Argentinian Jayme Alazraki's theory, which coins the term "neofantastic" for a derived form of old fantastical narratives, the one so widely theorized by Tzvetan Todorov.

Keywords: Supernatural. Fantastic. Neofantastic. Lygia Fagundes Telles.

Inventei tudo isso? Pergunto de novo. Um gato que sonha com o homem assim como o homem sonha com Deus.

(Lygia Fagundes Telles - As horas nuas)

1 Professor de Língua Portuguesa no Instituto Federal de Goiás-Campus Aparecida de Goiânia e doutorando no Curso de Pós-Graduaçẩo em Letras e Linguística da Universidade Federal de Goiás - UFG- Goiânia, Goiás.E-mail: juniorlit@hotmail.com 


\section{PALAVRAS INICIAIS}

Durante sua trajetória de mais de 60 anos dedicados à escrita, quatro vezes a escritora Lygia Fagundes Telles explorou a estrutura narrativa romanesca. A última delas foi em 1989, com o livro As horas nuas, romance tăo bem-sucedido como os outros, mas que possui um significado diferenciado, representando um momento ímpar na obra dessa escritora paulistana. Marcado por inovaçōes técnicas e temáticas, o livro dialoga intensamente com as principais tendências ideológicas e estéticas do final do século XX e início do XXI.

Apesar de suas especificidades, o quarto romance de Lygia Fagundes Telles năo representa uma cisấo com o que ela escrevera anteriormente. Na realidade, o que acontece é uma retomada intensa e complexa de estratégias, de temas, de personagens e de estruturas já habituais em sua escrita. Ao falar sobre o livro, a estudiosa Vera Maria Tietzmann Silva muito bem sintetiza a relaçâo desse livro com os outros escritos lygianos.

Semelhante na linguagem peculiar que torna os textos de Lygia inconfundíveis, semelhante também na reprise de personagens, temas e situaçóes, uma das marcas de seu mitoestilo. Essa tendência à reiteraçăo, contudo, ganha nesta obra um caráter superlativo, excedendo os limites observados em livros anteriores. No desenrolar da trama, o leitor familiarizado com as narrativas da autora pode vislumbrar alusóes claras ou veladas a todos os romances e a dezenas de contos diferentes, cobrindo praticamente toda a produçăo de Lygia. Significativa, entâo, se revela a epígrafe de Drummond que abre o volume dizendo: 'De tudo fica um pouco, năo muito'. (SILVA, 2009, p. 139)

Sem nenhuma dúvida, nesse romance, podemos identificar os lugares comuns tâo caros à escrita da artista, porém pode-se perceber que muitos deles săo apresentados de forma diversa, influenciados direta ou indiretamente pelas principais linhas de força da literatura daquele momento histórico.

Atenta às novas posturas e ideologias artísticas, além de totalmente fiel ao seu estilo único, Lygia Fagundes Telles traz para dentro de seu universo poético as mais atuais concepçôes e posicionamentos estéticos, engendrando uma ressignificaçâo de muitos expedientes típicos de sua escrita, o que se vê é uma gradativa sofisticaçăo no tratamento com a linguagem, com a forma e, acima de tudo, com o material humano ali tematizado. Dentre as constantes que sâo ali retomadas e ressignificadas em As horas nuas, buscamos analisar aqui aquela ligada à manifestaçăo do sobrenatural, algo que muito frequentemente - e de forma generalizada - é chamado de universo fantástico.

O sobrenatural é um recurso insistentemente explorado por Lygia Fagundes Telles, năo só essa insistência, mas, acima de tudo, a maestria com que esse expediente é trabalhado por ela fazem com que a paulistana seja considerada um dos mais representativos escritores do gênero, ao lado de outros como Murilo Rubiăo, J.J. Veiga e, atualmente, Marina Colasanti.

Na obra de Lygia, o sobrenatural tende a se manifestar especialmente em narrativas curtas, isto é, em contos, mas está presente também nos romances, mesmo que neles se manifeste de maneira mais tímida como acontece nos três primeiros. Um olhar panorâmico sobre a escrita lygiana nos mostraria que, apesar da recorrência constante, é possível identificar formas diferenciadas com que o insólito é trabalhado. A nosso ver, os contos de Lygia podem testemunhar as transformaçóes ocorridas 
no interior do gênero fantástico; mudanças que, alterando sentido e estrutura desse gênero, acabaram por engendrar uma evoluçăo no interior dessa forma narrativa, o resultado de tal renovaçăo interna vem sendo chamado de neofantástico, conforme proposto por Jaime Alazraki.

Sobre essa trajetória evolutiva testemunhada nos contos de lygianos, podemos dizer que, ao lado de narrativas notadamente tradicionais, inspiradas nos mestres Edgar Allan Poe e Machado de Assis, figuram outros bem diferenciados, seguindo as técnicas e concepçōes de grandes escritores do século XX, como Borges e Cortázar. Textos como "As formigas", "Natal na barca", "A mâo no ombro" e "Noturno amarelo" sâo exemplos de contos escritos ainda sob a influência da estética propagada pelos escritores oitocentistas; por outro lado, "Lua crescente em Amsterdâ", "Seminário dos ratos", "O crachá nos dentes" e "Anáo de jardim" săo textos que trazem em seu bojo traços pertencentes ao neofantástico, estética especificamente ligada ao século XX.

É a partir das perspectivas teóricas do neofantástico que percebemos o insólito no romance As horas nuas, isso porque tanto na composiçáo da obra como no seu conteúdo, o livro apresenta mais distanciamentos do que aproximaçôes em relaçâo à tradicional narrativa fantástica do século XIX, estética que, como afirma Todorov, "teve vida relativamente breve", já que sua primeira apariçâo sistemática se deu no fim do século XVIII e, um século mais tarde, encontrou "nas novelas de Maupassant os últimos exemplos esteticamente satisfatórios do gênero" (TODOROV, 2004, p. 175).

O fundamento dessa tendência literária narrativa chamada de fantástica eram enredos com uma atmosfera específica, pois se tratava de ambientes e situaçōes sombrios, muitas vezes, tenebrosos e amedrontadores, realidades facilmente encontradas nos textos de Poe, Hoffmann e Lovecraft, grandes representantes do gênero. Esse recurso estético foi amplamente explorado pelos escritores do final do século XVIII e aqueles de todo o século XIX.

No campo teórico e crítico, ele também foi estudado por renomados pesquisadores, olhares que, dentro de seus contextos históricos, foram influenciados por diferentes áreas do conhecimento. Sob a égide dessas diferentes visōes teóricas, grandes e importantes estudos foram, aos poucos, explorando os lugares comuns do fantástico, tanto do ponto de vista estrutural como do ponto de vista de seu sentido e valor, o que permitiu delinear os contornos mais significativos do gênero. Grande parte dessa teorizaçâo, porém, tinha como objeto de análise os textos do passado, aqueles pertencentes ao fantástico tradicional, cuja morte se encontra sentenciada por Todorov (2004). Desde o início do século XX, tanto no Brasil como no exterior, era possível ser rastreada uma transformaçáo no interior do gênero fantástico. Tais traços de inovaçâo foram amplamente explorados e aperfeiçoados por escritores no decorrer de todo o século em questăo, mas só na década de 1980 é que essas marcas foram sistematizadas por uma teoria e, juntas, constituíram a base do conceito estético de neofantástico, termo criado por Jaime Alazraki.

É partir da teoria defendida pelo pesquisador argentino que buscaremos promover uma leitura crítica do quarto romance lygiano, obra em que o metaempírico encontra-se trabalhado de modo diferenciado daquele presente em suas narrativas curtas. Vale dizer que, no enredo do livro, há duas manifestaçóes de caráter sobrenatural bem distintas, cada uma delas promove um impacto diferenciado na composiçáo e, 
principalmente, no valor estético da obra. Elas pertencem a núcleos diferentes, possuindo poucos pontos de contato entre si.

O primeiro desses dois fenômenos está ligado à narraçăo, apresentando o gato Rahul como narrador personagem de boa parte do livro, enquanto o segundo está centrado na psicóloga Ananta, ela mantém uma relaçâo incomum com o vizinho que mora no apartamento acima do seu. Os fatos relacionados a essa relaçâo, assim como a ideia que a moça tem do vizinho denunciam uma atmosfera de tom sobrenatural. Considerando a dimensâo deste trabalho, torna-se impossível uma análise de ambos os contextos, por isso, nos deteremos especificamente ao estudo da construçâo do narrador felino, recurso que, a nosso ver, constitui uma das mais importantes marcas de originalidade nesta obra.

\section{ALINHAVANDO VIDAS: O DISCURSO NEOFANTÁSTICO DE RAHUL}

Como já foi dito acima, as narrativas romanescas de Lygia Fagundes Telles, de certa forma, trazem em suas tramas aspectos ou resquícios de uma estrutura ligada à tradicional narrativa fantástica, principalmente àquela vertente derivada da loucura ou do misticismo. Isso acontece de modo bastante discreto nos três primeiros romances da autora, mas somente em sua quarta narrativa longa, As horas nuas, é que o sobrenatural se realiza de forma mais intensa, se impondo do início ao fim do enredo e sendo de suma importância para a realizaçăo do processo narrativo. Percebe-se, no livro, como o projeto e a concepçăo estética da obra têm como fundamento esse expediente literário, mostrando-se soberana sua importância no tecido textual criado pela artista.

Nessa narrativa, poucos sâo os vínculos com o fantástico de outrora, aquele típico das narrativas oitocentistas. Em vez deles, laços bem mais fortes parecem vinculá-la ao neofantástico, termo cunhado por Jayme Alazraki (1980), para conceituar uma tendência literária característica do século XX, derivada da estética fantástica, mas que, em muitos pontos, altera valores e elementos estruturais imprescindíveis ao antigo gênero.

O primeiro capítulo de As horas nuas nos apresenta a protagonista e narradora Rosa Ambrósio, uma mulher que, no passado, foi uma atriz de grande fama, mas que, no presente, já velha, vivencia todo o drama de sua decadência física, psicológica e afetiva. Nessa primeira parte da obra, o leitor acredita estar diante de um livro cuja estrutura seria autobiográfica, tem-se a impressâo de que As horas nuas seja um romance memorialístico sobre a vida de Rosa e, diante dessa possibilidade, náo se cogita nenhuma irrupçăo de caráter insólito.

O segundo capítulo, entretanto, apresenta uma situaçăo inusitada, percebe-se a apariçấo de uma nova voz narrativa cujo dono é, em si, um narrador muito incomum, isso porque ele é Rahul, o gato de estimaçăo da atriz decadente. $O$ fato de termos um animal como narrador, sendo o dono de uma voz e de uma consciência narrativa, faz com o romance assuma imediatamente marcas de ordem sobrenatural, um universo regido por leis e sentidos diferentes daqueles do cotidiano, cotidiano esse em que os animais năo possuem capacidade de falar. Com a apariçấo desse gato narrador, logo no segundo capítulo do livro, é possível perceber uma primeira ruptura com o fantástico tradicional teorizado por Tzvetan Todorov (2004) em seu trabalho Introduçâo à literatura fantástica. 0 pesquisador, baseando-se no que fora exposto por Penzoldt, defende haver nesse gênero o que pode ser entendido como uma estrutura gradativa 
segundo a qual o enredo parte de uma ambientaçăo trivial para, aos poucos, alcançar seu ponto culminante, este representado pelo evento sobrenatural, promotor de uma desestabilizaçáo do cotidiano ordinário. Essa estrutura gradativa do fantástico pode ser facilmente identificada nas narrativas de Edgar Allan Poe, a quem coube o papel de grande escritor e de erudito teórico do gênero. É possível dizer que uma parte significativa dos escritores contemporâneos tem como influência toda a poética elaborada por esse inconfundível autor de contos fantásticos.

Assumindo o posto de narrador no início do livro e mantendo-o até fim da obra, Rahul engendra uma ruptura com a antiga organizaçăo estrutural fantástica. Em contrapartida, tal aspecto inovador vincula-se, de imediato, ao modus operandi da estética neofantástica. Jaime Alazraki (1990) explica que as narrativas contemporâneas trazem em si um elemento fantástico, entretanto este se diferencia daquele do passado por apresentar uma "visión", uma "intensión" e um modus operandi diferenciados. De acordo com o estudioso, no fantástico canônico, a "visión" parte da solidez de um mundo real e, em oposiçăo a ele, insurgem os elementos sobrenaturais; dessa colisăo é gerado um choque entre universos bem distintos e pouco conciliáveis. Enquanto isso, no neofantástico, a relaçăo entre os acontecimentos e o mundo real é alterada já que "lo neofantástico assume el mundo real como una máscara, como un tapujo que oculta una segunda realidad que es el verdadeiro destinatario de la narración neofantástica" (ALAZRAKI, 1990, p.29). Para essa estética, o "real" seria uma mera "máscara" para uma realidade outra que se faz eclipsada e mais complexa. Sobre essa outra realidade estaria a tônica da narraçăo neofantástica, isto é, sobre o que se mostra velado pela aparente realidade. Aqui năo há oposiçăo ou choque, os dois universos encontram-se simultâneos, um sofrendo a intervençăo do outro sem se promover nenhum tipo de colisâo ou hecatombe.

No discurso literário da estética neofantástica, mais do que uma intervençâo de uma ordem na outra, ocorre um perfeito amálgama entre ambas. Náo há contestaçáo nem rachaduras, uma é tăo coerente quanto a outra e, nessa simultaneidade, elas se complementam, tornando-se elementos comuns e contíguos. Essa relaçâo entre as duas pode ser facilmente percebida na composiçấo do tecido discursivo do livro de Lygia Fagundes Telles. O romance é dividido em dezoito capítulos, sete deles possuem Rosa como narradora enquanto outros seis sáo narrados por Rahul. Ainda que Rosa tenha como centro de suas memórias sua vida, a presença de Rahul nelas é constante, ora ele aparecendo como personagem coadjuvante nos eventos, ora atuando como ouvinte/companheiro, com quem a narradora conversa dividindo suas lembranças e confissōes. $O$ mesmo acontece no que é expresso pelo gato; ao relembrar suas vidas passadas, ele traz para seu discurso comentários, eventos ou reflexóes relacionados à Rosa Ambrósio. Um pouco de cada um desses dois personagens/narradores é preenchido pelo discurso do outro, pelo testemunho desse outro. Fica evidente a total cumplicidade entre os dois, o que se evidencia inclusive nas falas de ambos: "Se pudesse, passava um telegrama para Diogo Torquato Nave Onde Ele Estiver: Rosa Ambrósio depende de você e eu dependo dela para viver. Ponto. Quer ter a bondade de aparecer? Assinado, Rahul" (TELLES, 2010, p. 68).

Outro ponto que pode ser usado para ratificar a convivência pacífica entre os dois universos explorados no discurso de cada um dos narradores é o próprio conteúdo. Em ambos os casos, temos narrativas memorialísticas marcadas pelos mesmos traços, sâo 
narraçóes que tematizam a decadência sofrida pela atriz e pelo gato. Enquanto Rosa vê sua carreira e sua beleza sendo levadas pelo tempo, Rahul relembra um passado distante em que tinha uma forma humana e agora vivencia a humilhaçăo de estar preso a um corpo animal privado de qualquer liberdade e, em especial, privado de fala. $\mathrm{Na}$ abordagem de suas angústias particulares, essas duas vozes - de Rosa e de Rahul - se entrecruzam, criando a sensaçấo de uma ser a continuaçăo da outra, trata-se de um fio condutor narrativo de pura unissonância.

Essa ausência de choque ou de conflito entre dois planos tâo diferentes, de certa forma, também contribuiu para que outro traço fantástico assumisse novo valor no terreno da narrativa neofantástica. A intención que Alazraki defendia existir na estética fantástica estaria voltada para a promoçăo do sentimento de medo. Em seus ambientes, suas atmosferas e seus personagens sobrenaturais, o fantástico tinha como uma de suas constantes o jogo com o terror, sendo este considerado um dos pilares do gênero para muitos dos críticos e dos teóricos que sobre o gênero se debruçaram. Nas narrativas pós-oitocentistas - aquelas que foram escritas no decorrer do século XX, período em que foram testemunhadas duas grandes guerras mundiais -, o medo nâo tem sua origem em outra realidade senâo naquela do cotidiano. Aliás, é preciso dizer que, em vez de terror, observamos as personagens experimentando outro impacto em relaçăo às manifestaçōes metaempíricas. Como explica Alazraki, tais manifestaçōes

[s]on, en su mayor parte, metáforas que buscan expressar atisbos, entrevisiones o interstícios de sirazón que escapan o se resisten al linguaje de la comunicación, que no caben en las cedillas construídas por la razón, que van a contrapelo del sistema conceptual o científico con que nos manejamos a diário. (ALAZRAKI, 1990, p.29)

O fato de Rahul ser um gato e poder contar histórias sobre suas vidas passadas náo busca assustar ou amedrontar o leitor. Nem ao gato, que já fora um dia humano, soa estranho o fato de se perceber num corpo de animal, mantendo sua percepçâo e consciência humanas. O seu narrar flui sem contestaçăo ou surpresas amedrontadoras, os eventos sucedem-se sem a promoçăo de nenhum espanto nem para o leitor nem para o narrador-personagem:

Um rio pardacento. 0 menino mergulha nessas águas. Ouço com alegria o ruído vigoroso de minhas braçadas, estou nu na correnteza. O bosque. Entrei no rio menino e dele saio um jovem, mas esse prodígio náo me abala, só me ocupa um pensamento, o que vem pela frente? (TELLES, 2010, p. 28).

Na realidade, os eventos causadores de comoçâo terrificante săo aqueles que envolvem a vida de Gregório, ex-marido de Rosa Ambrósio. Ele foi vítima da ditadura, foi torturado a ponto de sofrer impactos profundos em sua personalidade. Além disso, a violência sofrida, mais do que lhe promover muita dor, fez com que o professor universitário desenvolvesse uma doença degenerativa, o Mal de Parkinson.

O pobrezinho. Nunca mais foi mesmo. Saiu da prisăo diferente, mais fechado, mais calado, ô! meu Pai, mas o que fizeram com ele!? Atingido no tinha de mais precioso, a cabeça, sentia dores. A mâo tremendo tanto, disfarçava quando acendia o cachimbo, o que fizeram?! (...) (TELLES, 2010, p. 40).

Foi essa situaçăo absurda que o levou a optar pelo suicídio. Percebe-se, com isso, que o princípio desestabilizante náo deriva de uma realidade outra desconhecida e representada 
num evento de ordem sobrenatural. Se há medo ou terror no neofantástico, ele deriva de eventos e de indivíduos pertencentes ao comum, ao cotidiano, por isso, tal expediente assume o valor de um testemunho. Com isso, entende-se que pode ser relacionada à estética neofantástica a funçăo de expressar uma nova percepçâo do mundo; como um arauto, ela propaga um mal-estar na civilizaçăo contemporânea, sentimento de inquietaçăo que nâo deriva do desconhecido, mas do comum tâo reconhecido no cotidiano.

Nem mesmo as apariçōes fantasmagóricas - um dos lugares-comuns da tradiçāo sobrenatural fantástica - constituem elementos promotores de medo. No interior do apartamento em que vive com Rosa Ambrósio, Rahul frequentemente se depara com a presença de espectros que por ali passeiam. O apartamento da atriz náo recebe apenas a visita de estranhos, mais de uma vez Rahul vê Gregório andando pela sua antiga casa.

Os fantasmas de As horas nuas năo retomam aqueles da tradiçăo, eles năo săo figuras ameaçadoras ou horrendas, nâo possuem atitudes de contravençáo, náo almejam assustar ou se vingar dos vivos. Numa convivência pacífica, vivos e mortos dividem o mesmo espaço, mas o único a testemunhar essa realidade é o gato. Pelo prisma desse olhar animal, o valor dessas almas é ressignificado; distantes das antigas figuras promotoras de medo, elas assumem até mesmo auras benfazejas.

A menina antiga está me vendo mas năo faz o menor movimento, está apenas olhando. (...) Baixa o olhar inexpressivo para o pequeno bastidor com o bordado, por quem ela espera? Um fantasminha nem feliz nem infeliz. Calmo. O velho do chapéucoco, a mulher do xale, Gregório com seu cachimbo - demostraram todos nas suas apariçóes que a alma ou corpo sutil, tenha isto o nome que tiver, vai se desfazendo antes ainda de se desfazer o corpo material (TELLES, 2010, p. 126).

Se nas narrativas fantásticas tradicionais havia uma hesitaçăo assim como um constante sentimento de terror, isso ocorria porque esses dois expedientes eram usados como símbolos de uma concepçáo de mundo específica da cultura daquele período histórico, ou seja, eles representavam a condiçáo frustrante do homem que confiou por completo nas certezas da ciência e que, diante das limitaçôes dela, se viu ainda ameaçado por um mundo misterioso, repleto de lacunas. No neofantástico, por outro lado, o terror năo se faz tăo significativo. A descrença no conhecimento científico continua, mas agora intensificada. A ciência năo só pode ser contestada como também é tratada com certo descrédito em alguns pontos, nâo podendo ser entendida como verdade absoluta, mas apenas como uma das muitas possibilidades usadas pelo homem para se relacionar com mundo. Essa postura cética pode ser identificada na seguinte fala de Rosa, quando ela se dirige a seu amante Diogo, depois de este fazer uma afirmaçấo embasada em pesquisas: " - Ora, Diogo, você ainda acredita em pesquisas? Desde que o primeiro homem começou a envelhecer esses pesquisadores pesquisam a cura da velhice, a pior das doenças. Até o Diabo foi invocado mil vezes. Descobriram? Hein?!..." (TELLES, 2010, p. 31). Deve-se dizer, porém, que o descrédito do indivíduo contemporâneo náo se volta apenas contra a ciência, mas contra todas as suas antigas e atuais formas de conhecimento, depois de ver todos os seus aportes falharem, o homem nâo acredita fielmente em mais nada, e isso o deixa a mercê de qualquer sorte, tornando-o livre para também acreditar em tudo. Diante disso, tornam-se altamente emblemáticas as palavras de Rahul: 
Eu disse a gente. Porque a ideia de ser de novo um bicho é tăo dilacerante que continuo a me perguntar, no mesmo tom culposo da Rosona, o que fiz, o que?! para merecer esta forma. E năo tenho fé, náo acredito em nada. Um gato memorialista e agnóstico - existe? Memória que quase sempre é peçonha na qual me alimento. E me enveneno. Recuei. Saltei para o tapete. Agora tenho medo da liberdade (TELLES, 2010, p. 125-126).

O neofantástico é uma atualizaçăo do fantástico, entretanto, sobre as duas formas narrativas, ainda resta ser feita uma explicaçăo, algo relativo ao plano estritamente estético. No gênero fantástico, em que há um comprometimento com o que se pode ver, encontramos um vínculo forte entre o texto e a realidade, ou seja, o fictício tem como base um plano real ao qual se vincula, buscando ser um reflexo dele. No neofantástico, os elos entre a realidade e a ficçăo se dissociam por completo. Estamos diante de uma criaçăo, uma elaboraçâo artística cuja coerência é interna e nâo externa, assim a fruiçâo do texto neofantástico acontece de modo bem diferente. Italo Calvino (2015), ao falar sobre a nova relaçâo do leitor com o texto de caráter sobrenatural, explica de que modo acontece essa apreciaçăo.

Sentimos que o fantástico diz coisas que se referem diretamente a nós, embora estejamos menos dispostos do que os leitores do século passado a nos deixarmos surpreender por apariçóes e fantasmagorias, ou melhor, estamos prontos a apreciálas de outro modo, como elementos da cor da época. (CALVINO, 2015, p. 181)

Com o propósito de melhor tematizar as inquietaçōes do indivíduo pertencente a um contexto tâo secular, o neofantástico se humanizou intensamente, ele se nutriu de uma carga psicológica complexa, algo que Todorov năo considerava comum ao fantástico tradicional, por isso o teórico năo inseriu Kafka na lista de escritores fantásticos, vendo nele tais traços de psicologismo. Ao contrário de Todorov, Calvino reconhece e exalta o aspecto psicológico contido nas recentes manifestaçôes do sobrenatural:

Assim como o conto filosófico tinha sido a expressăo paradoxal da Razăo iluminista, o conto fantástico nasceu como um sonho de olhos abertos do idealismo filosófico, com a declarada intensáo de representar a realidade do mundo interior, subjetivo, conferindo a ele uma dignidade igual ou maior à do mundo da objetividade e dos sentidos. Também ele é conto filosófico, pois, e continua sendo até hoje, mesmo atravessando todas as mudanças da paisagem intelectual (CALVINO, 2015, p. 202).

Se o conto fantástico do passado constituía uma maneira de repensar a realidade, no decorrer do século XX, o sobrenatural foi se refinando, tornando ainda mais complexa e filosófica essa reflexáo sobre o real circundante. Presente nos mais variados gêneros, a manifestaçấo sobrenatural perdeu sua aura de fenômeno, de acontecimento, para assumir ares de forma de conhecimento, modo de sabedoria, ligando-nos ao nosso íntimo existencial: "À nossa sensibilidade de hoje, o elemento sobrenatural que ocupa o centro desses enredos aparece sempre carregado de sentido, como uma irrupçáo do inconsciente, do reprimido, do que se distanciou de nossa atençăo racional" (CALVINO, 2015, p. 181).

Conceder a um gato a funçâo de narrador nâo deve nos causar estranhamento, é uma atitude que apenas cria a possibilidade de explorar e alcançar abismos humanos nele representados. Rahul nâo é somente um gato, ele é um gato humanizado, atravessado pelos mistérios e pelas lacunas da existência humana, ele é um arauto 
de nossa condiçăo. Liberto de nossos grilhōes sociais e psicológicos, ele se encontra livre para explorar os mais recônditos e obscuros labirintos da nossa essência: "A única vantagem do bicho sobre o homem é a inconsciência da morte e da morte eu estou consciente. Resta-me o consolo da morte sem bagagem, deixo uma coleira antipulga. Duas vasilhas e uma almofada" (TELLES, 2010, p. 125).

Tzvetan Todorov, ao definir as funçôes essenciais do fantástico, defende que, à primeira vista, a principal delas seria de caráter tautológico. Assim, o gênero "permite descrever um universo fantástico, e este universo nem por isto tem qualquer realidade fora da linguagem; a descriçâo e o descrito nâo sāo de natureza diferente" (TODOROV, 2004. p.101). Acreditamos que, na literatura do século XX, esse caráter tautológico tenha se intensificado tanto, a ponto de poder ser considerado a pedra fundamental das narrativas neofantásticas. Dando continuidade à tautologia do fantástico, o neofantástico possibilita a descriçâo de um universo que só existe enquanto construçâo linguística neofantástica, năo se fazendo necessárias nem obrigatórias as pontes com o mundo palpável. Nesse sentido, se justificam as palavras de Todorov quando diz que "a literatura do século XX é, num certo sentido, mais 'literatura' que qualquer outra" (TODOROV, 2004. p.177). Preso ainda a uma concepçâo de arte como projeçâo ou espelhamento da realidade, o sobrenatural presente nas narrativas oitocentistas era aquele comprometido com o que se podia ver, centrado naquele antigo e racional apego à materialidade empírica.

\footnotetext{
É como se conto fantástico, mais que qualquer outro gênero narrativo, pretendesse "dar a ver", concretizando-se numa sequência de imagens e confiando sua força de comunicaçăo ao poder de suscitar "figuras". O que conta năo é tanto a mestria na manipulaçấo da palavra ou na busca pelos lampejos de um pensamento abstrato, mas a evidência de uma cena complexa e insólita (CALVINO, 2002, p. 186).
}

Das palavras de Italo Calvino, podemos depreender que o compromisso da estética fantástica era mais concentrado no plano da arte plástica do que na elaboraçăo discursiva literária. Voltando-se para construçăo de cenas, o discurso fantástico ainda tinha como referência uma realidade. Observamos, em As horas nuas, uma realizaçâo estética bem mais intensa, isso porque a manifestaçăo sobrenatural se concretiza enquanto discurso e năo enquanto imagem. Superado esse vínculo com a realidade, no livro de Lygia Fagundes Telles, encontramos um sobrenatural que năo é oriundo de experiências visuais, ele se torna fruto de uma condiçăo, um estado de contato com o mundo que, consubstanciado na imagem de um gato com consciência humana, sugere o tăo sonhado e almejado estado original em que homem e natureza pertenceriam a uma única unidade, isto é, ao uno original.

Concedendo fala a um gato, o que Lygia Fagundes Telles engendra nâo é a criaçăo de uma cena, mas de um discurso. Rahul năo fala como os humanos nem mesmo com os humanos. Ainda que ele seja o interlocutor de Rosa, em vários momentos do livro, ele năo é visto "falando" - se isso acontecesse, aí, sim, teríamos uma cena fantástica tradicional. Entretanto, ele fala consigo e nisso se faz projetada uma condiçăo neofantástica, isso porque nâo se cria uma outra realidade, apenas concede-se expressividade a algo já existente e simultâneo, mas eclipsado pelo conhecido e trivial.

Se a apreciaçáo do sobrenatural mudou, isso se deu porque os valores estéticos usados na sua composiçâo, assim como seus objetivos, também se tornaram outros. 
Todorov já chamava a atençăo para a complexidade da literatura do século passado, se ela era mais literatura que as de outras épocas isso de se deu por esse caráter tautológico assumido pela arte contemporânea, algo que promoveu uma imersăo profunda em seu próprio universo, debruçando-se sobre si mesma, num processo de autorreferenciaçăo.

Ainda de acordo com o teórico búlgaro, o fantástico tinha como um de seus pilares a noçấo de causalidade, ou seja, os acontecimentos descritos năo poderiam ser derivados do mero acaso ou da sorte, eles precisavam, no mínimo, apresentar uma relaçăo generalizada entre si, algo que o pesquisador chamou de pandeterminismo. Em decorrência disso, surgem, nas narrativas, seres poderosos, superiores aos homens, suas açôes extraordinárias justificam o que as leis da vida cotidiana năo conseguem explicar. Eles se tornam a explicaçăo para o que antes se fazia inexplicável.

Essa causalidade encontra-se bem ao gosto do cientificismo dos séculos XVIII e XIX, quando se necessitava de uma explicaçâo para tudo, cabia à ciência explicar toda a realidade que cercava o homem, apresentar as certezas e indicar as verdades. Diante do fracasso dessa postura científica, outras concepçóes foram buscadas, as verdades e as certezas questionadas. $O$ ceticismo do indivíduo contemporâneo năo acredita em mais nada, mas também náo duvida de tudo. O sobrenatural encontrado em As horas nuas é aquele despido de finalidade, náo se encontra nele o compromisso de determinar a causalidade dos eventos, trata-se de um posicionamento que se apresenta intensamente fundamentado no caráter estético e muito pouco na vertiginosa postura racional.

\section{A TÍTULO DE CONCLUSÃO}

O século XX estabeleceu um contexto sociocultural responsável por um número sem igual de transformaçōes ideológicas em todas as áreas do conhecimento. Na arte, năo foi diferente, em especial na Literatura. Nesse momento histórico em que o homem e o mundo ao seu redor tornaram-se outros, as formas e as concepçōes literárias precisaram se modificar para melhor testemunharem as condiçōes de um mundo diferente. A reelaboraçăo de uma estrutura narrativa é consequência direta de outra compreensâo de mundo, a forma literária apenas reflete os valores com que os indivíduos reorganizam sua relaçăo com o circundante. Assim como a narrativa mítica num certo momento náo conseguiu mais expressar e representar o universo do homem antigo, as narrativas fantásticas também sofreram o impacto de novas concepçôes, sendo exigidos valores e elementos outros para expressá-las.

Em sua escrita, Lygia Fagundes Telles demonstra quâo ampla pode ser a exploraçấo dos limites do expediente sobrenatural. Em contos e romances, de modos diferenciados e em diferentes intensidades, o metaempírico se faz presente concedendo ao tecido literário lygiano uma aura de discurso mítico, de universalidade e de ambiguidade, sem nunca abrir măo do compromisso com a elegância e com a profundidade. Nesse compromisso com os mistérios de nossa condiçâo, a escrita lygiana nâo se assemelha ao discurso científico com suas respostas precisas e verificáveis, ela retoma muito mais o discurso oracular que, em vez de respostas, se pronunciava a partir de enigmas, sempre abertos a um número infinito de interpretaçōes.

Em entrevista, a própria escritora evidencia sua paixăo pelo indecifrável, traço que busca imprimir aos seus escritos: “O bonito na história é a ambiguidade, a indecisâo, a 
dúvida em relaçăo à personagem. Esse tipo de literatura me apaixona e é isso que eu espero ter, em alguns contos, conseguido atingir" (MOURA, 1996, p.125). No intuito de assim escrever, o sobrenatural se faz uma ferramenta de suma importância para essa escritora, servindo de matéria prima de seu universo ficcional tăo particular.

Recorrer ao sobrenatural é optar por uma vertente estética em que a relaçăo entre a linguagem e o real se torna mínima, o que se narra năo é imitaçăo, cópia ou espelhamento. Aqui o discurso literário alcança seu valor máximo de literariedade, já que sua única referência é seu próprio sistema, com suas próprias regras e sentidos. Se há um compromisso bem definido, ele está centrado na busca por narrar mundos possíveis, nâo o mundo real.

O romance de Lygia Fagundes Telles é um bom exemplo das inovaçôes estruturais e ideológicas sofridas no interior da narrativa sobrenatural. O livro As horas nuas representa um momento específico no trajeto evolutivo do gênero, evoluçâo ainda em curso. Com o termo evolutivo, náo almejamos promover um julgamento valorativo em que a forma atual se encontre mais valorizada do que a do passado, ou vice-versa, pois o entendemos apenas como uma maneira de perceber um processo dinâmico no interior da forma que, no decorrer do tempo e de mudanças culturais, sofreu variaçôes que lhe alteraram elementos e sentidos que antes se faziam fundamentais na estrutura tradicional, tornando necessários outros que os substituíssem, vendo nesse processo talvez o mais importante de todos os traços da arte literária, a capacidade de sempre se fazer nova e inovadora.

\section{REFERÊNCIAS}

ALAZRAKI, Jaime. ¿Qué es lo fantástico?. In: Mester, vol. XIX, n. 2. 1990, p. 21-33.

CALVINO, Italo. Mundo escrito e mundo nâo escrito: artigos, conferências e entrevistas. Organizaçăo Mario Barenghi. Traduçăo Maurício Santana Dias. 1. ed. Săo Paulo: Companhia das Letras, 2015.

MOURA, Sheila. Lygia Fagundes Telles: uma mulher de palavra. Revista Desfile. n. 318, Sáo Paulo: 1996, p.124-125.

SILVA, Vera Maria Tietzmann. Dispersos \& inéditos: estudos sobre Lygia Fagundes Telles. Goiânia: Cânone Editorial, 2009.

TELLES, Lygia Fagundes. As horas nuas. Sáo Paulo: Companhia das Letras, 2010.

TODOROV, Tzvetan. Introduçâo à literatura fantástica. Traduçâo de Maria Clara Correa Castello. 3.ed. Sâo Paulo: Perspectiva, 2004. (Debates; 98, dirigida por J. Guinsburg).

Submetido em 22 de março de 2018 Aceito em 17 de maio de 2018 